\title{
Article \\ A Switchable Cholesteric Phase Grating with a Low Operating Voltage
}

\author{
Ho-Jin Sohn ${ }^{\dagger}$, Seung-Won $\mathrm{Oh}^{\dagger}{ }^{\dagger}$, Yeongyu Choi, Seong-Min Ji and Tae-Hoon Yoon $*$ (D) \\ Department of Electronics Engineering, Pusan National University, Busan 46241, Korea; \\ sonhojin159@pusan.ac.kr (H.-J.S.); ohseungwon@pusan.ac.kr (S.-W.O.); choiyg@pusan.ac.kr (Y.C.); \\ jisungmin@pusan.ac.kr (S.-M.J.) \\ * Correspondence: thyoon@pusan.ac.kr \\ t These authors contributed equally to this work.
}

\section{check for} updates

Citation: Sohn, H.-J.; Oh, S.-W.; Choi, Y.; Ji, S.-M.; Yoon, T.-H. A Switchable Cholesteric Phase Grating with a Low Operating Voltage. Crystals 2021, 11, 100. https://doi.org/10.3390/cryst 11020100

Received: 25 December 2020

Accepted: 21 January 2021

Published: 25 January 202

Publisher's Note: MDPI stays neutral with regard to jurisdictional claims in published maps and institutional affiliations.

Copyright: (c) 2021 by the authors. Licensee MDPI, Basel, Switzerland This article is an open access article distributed under the terms and conditions of the Creative Commons Attribution (CC BY) license (https:// creativecommons.org/licenses/by/ $4.0 /$ )

\begin{abstract}
We demonstrate a simple fabrication method of a uniform-lying-helix (ULH) cholesteric liquid crystal (ChLC) cell for phase grating device applications. To utilize a stable ULH state, we set the pitches of ChLCs as half of the cell gap to obtain the fingerprint texture with homeotropic anchoring. With the given grating period, the diffraction efficiency of the ULH cell can be maximized by optimizing the cell gap. We found that the fabricated grating device can provide a large diffraction angle of $10^{\circ}$ and a low operating voltage of $3 \mathrm{~V}$ with a diffraction efficiency of $30 \%$. We expect potential applications of the device for diffraction optics, optical interconnects, and beam steering devices.
\end{abstract}

Keywords: liquid crystals; cholesteric liquid crystal; uniform-lying-helix cholesteric liquid crystal; diffraction

\section{Introduction}

Cholesteric liquid crystals (ChLC) have always been actively studied because of their helical structure. Recently, interest in ChLCs has grown due to their possible non-display applications, such as beam deflectors [1], controlled mirrors [2], light shutters [3-7], laser elements [8-13], and diffraction grating elements [14-17]. ChLCs commonly exhibit three different textures depending on the boundary conditions and the pitch: planar, fingerprint, and focal-conic textures. In the planar state, the liquid crystals (LCs) align parallel to the substrates so that the helical axis is perpendicular to the substrates. In this state, ChLCs exhibit light reflection along the helical axis provided; the wavelength is set by the pitch.

In the fingerprint state, the axis of the helical superstructure is parallel to the substrates. Usually, the helical axis orientation is degenerate, i.e., they can be aligned randomly, yielding a polydomain sample. A uniform lying helix (ULH) structure has a unique direction of the helical axis [18]. In this state, the effective refractive index periodically changed along the helical axis. Consequently, in such a configuration, the ChLC cell acts as a diffraction grating. When the pitch length of ChLCs is changed by various external stimuli, such as the electric field, temperature, light, and humidity, the diffraction angle can also be controlled. Since the late 1980s, the problem of obtaining a stable and uniform ULH texture has been reported. It requires cooling the LCs from the isotropic phase while applying an electric field to obtain the ULH texture. Mechanical shearing [19] and polymer stabilization [20-23] have been proposed to stabilize the ULH structure.

In this paper, we propose an LC phase grating device with a large diffraction angle and low operating voltage. The phase grating was realized with the ULH state of ChLC. To utilize a stable ULH state, we set the pitches of ChLCs as half of the cell gap, where ChLCs show the fingerprint state with homeotropic anchoring. We fabricated an LC cell with the mechanical rubbing to give the orientation preference of the helical axis perpendicular to the rubbing direction. We confirmed the alignment of the ULH state with polarized optical microscope (POM) images. We measured the diffraction angle and efficiency as we varied the pitch of the cell. We found that, with the given grating period, the diffraction 
efficiency of a ULH cell can be maximized by optimizing the cell gap. We confirmed that the fabricated grating device exhibited a large diffraction angle of $10^{\circ}$, a low operating voltage of $3 \mathrm{~V}$, and diffraction efficiency of $30 \%$.

\section{Cell Fabrication}

To fabricate a ChLC cell in the ULH state, it is necessary to align the helical axis of the ChLCs parallel to the substrate. Uniform homeotropic alignment can support the configuration in which the helical axis is parallel to the substrates. However, if the chiral dopant is not sufficient, the ChLCs cannot maintain the chiral state. The minimal helical pitch length $p_{t h}$ for the homeotropic state can be expressed as $p_{t h}=2 d k_{2} / k_{3}$ [24-28], where $d$ is the cell gap, and $K_{2}$ and $K_{3}$ are the twist and bend elastic constants, respectively. If the pitch length is longer than the $p_{t h}$, the chiral torque is too weak. Therefore, the LCs are unable to twist, and the LC cell shows the homeotropic alignment of LCs. When the pitch length is shorter than $p_{t h}$, the chiral torque is sufficiently strong. Therefore, the various chiral structures, such as fingerprint state and focal-conic state, can be observed. Figure 1 depicts the transmittance and POM images of LC cells with the homeotropic anchorings as functions of the $d / p$. The transmittance was measured as the ratio of the incident light intensity and the transmitted light without polarizers. The transmittance of the LC cell decreased with the increase in $d / p$ because of the light scattering in the fabricated LC cell. To utilize a stable ULH state with homeotropic anchoring, we set the pitches of ChLCs as $d / p=2$ for which the cell is in the fingerprint state.

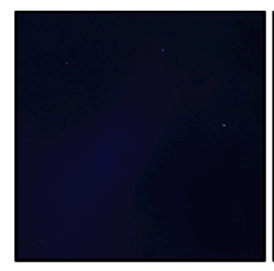

$d / p=1.0$

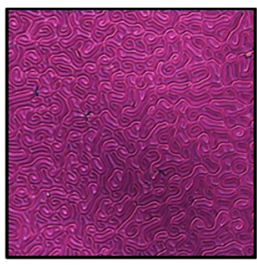

$d / p=2.0$

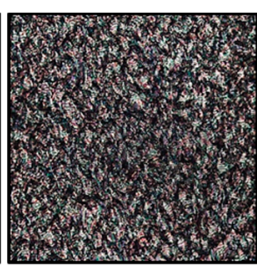

$\mathrm{d} / \mathrm{p}=\mathbf{8 . 0}$

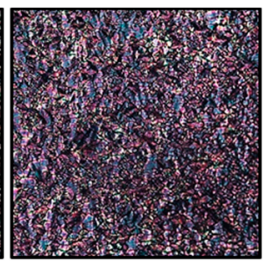

$d / p=16$

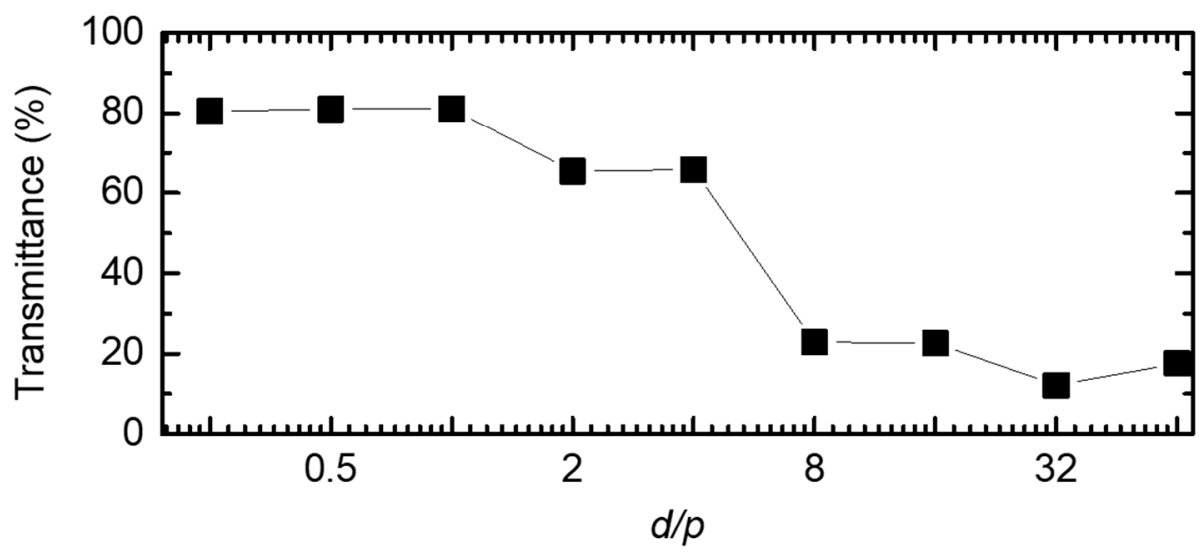

Figure 1. Transmittances and polarized optical microscope (POM) images of liquid crystal (LC) cells with homeotropic anchorings as functions of the $d / p$ (the ratio of the cell gap and pitch length). LC cells were fabricated using an achiral nematic LC (E7) and a chiral dopant (S811) with a fixed cell gap of $10 \mu \mathrm{m}$.

The nematic LC E7 (Merck) (dielectric anisotropy $\Delta \varepsilon=13.8$, refractive indices $n_{0}=1.52$ and $n_{e}=1.75$, elastic constants $K_{1}, K_{2}$, and $K_{3}$ are $10.3,7.4$, and $16.5 \mathrm{pN}$, respectively) was doped with chiral dopant R5011 (HCCH), which has a high helical twist power of about $117 \mu \mathrm{m}^{-1}$, to obtain a ChLC with a pitch length of $0.16 \sim 20 \mu \mathrm{m}$. The LC mixture was stirred continuously for $24 \mathrm{~h}$ at $120^{\circ} \mathrm{C}$. The mixture was then filled into an empty cell at $70^{\circ} \mathrm{C}$. The empty cells were fabricated using ITO coated glasses. The thickness of the $\mathrm{ChLC}$ layer was fixed to $10 \mu \mathrm{m}$. ITO-coated glass slides were spin-coated with homeotropic polyimide, SE-5662 (Nissan chemical), for vertical anchoring at the surface. Spin coating 
was made at $4500 \mathrm{rpm}$ for $50 \mathrm{~s}$. Then, ITO-coated glass slides were baked at $230{ }^{\circ} \mathrm{C}$ for 1 hour. By employing suitable protocols, the ULH state can be achieved from polydomain fingerprint textures. Mechanical rubbing can give orientation preference of the helical axis perpendicular to the rubbing direction [29]. The rubbing condition was set as follows: the average values of the fiber diameter, the fiber length, and the fiber density were $15 \mu \mathrm{m}$, $2.5 \mathrm{~mm}$, and $1040 \mathrm{~cm}^{-2}$, respectively. The diameter of the rubbing roller and the rubbing depth were 60 and $0.25 \mathrm{~mm}$, respectively. The rotation speed of the roller was $800 \mathrm{rpm}$ and the substrate proceeding speed was $33 \mathrm{~mm} / \mathrm{s}$, respectively. Therefore, we used this rubbing method for ULH alignment.

\section{Results and Discussion}

We compared the diffraction characteristics by controlling the pitch length between 1.25 and $10 \mu \mathrm{m}$. A He-Ne laser (Newport) emitting $\lambda=543 \mathrm{~nm}$ was used as a probing beam with a polarizer. The transmission axis of the polarizer was set perpendicular to the helical axis of ULH cells. During the optical measurement, fabricated ULH cells were driven by a square-wave voltage at $1 \mathrm{kHz}$.

The obtained ULH textures were visually captured by observation of the sample using a polarized optical microscope (POM). As shown in Figure 2a, POM images of the fabricated cell showed well-formed periodic structures with the pitches as designed. The measured grating periods $\Lambda$ of the ULH cells were $2.5,5,10$, and $20 \mu \mathrm{m}$, which are twice the cholesteric pitches, respectively, because the helix could be distorted by confining ChLCs between the two substrates coated to produce homeotropic boundary conditions [25]. To further the dependence of a ULH grating on the grating period $\Lambda$, polarized light from the green laser is normally incident to the cell. The diffraction pattern was captured with a digital camera. As shown in Figure 2b, it was confirmed that the smaller the grating period, the narrower the interval between each pattern.

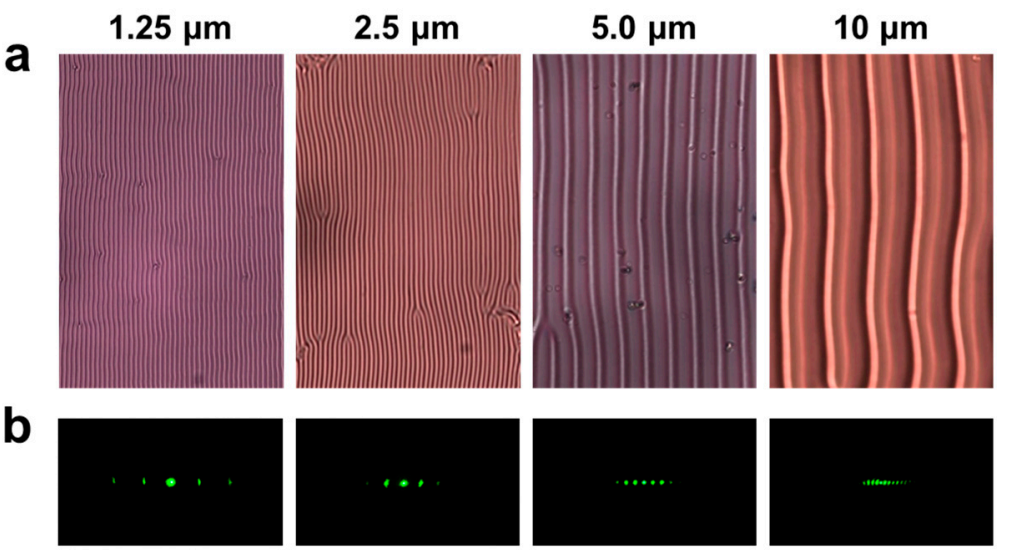

Figure 2. (a) POM images and (b) diffraction patterns of the fabricated uniform-lying-helix (ULH) cells (the pitches are set as 1.25, 2.5, 5.0, and $10 \mu \mathrm{m}$ ). The thickness of LC cells was set as twice the pitch.

We investigated the diffraction angle and the first-order diffraction efficiency. The diffraction efficiency is the ratio of the first- to the zeroth-order diffraction intensities, as represented by $\eta=I_{1} / I_{0} . I_{0}$ and $I_{1}$ are the zeroth-order and the first-order diffraction efficiencies, respectively. Figure 3 shows the diffraction angles of fabricated ULH cells as a function of the grating period $\Lambda$. The increase in the grating period $\Lambda$ was accompanied by the decrease in the diffraction angle $\theta$ (dots). To compare the measured results, we calculated the diffraction angles with

$$
\sin \theta=\frac{\lambda}{\Lambda}
$$


where $\lambda$ and $\Lambda$ are the wavelengths of the probe beam and grating period of the diffraction grating element, respectively [30]. The calculated diffraction angles show good agreement with the measured results, as shown in Figure 3.

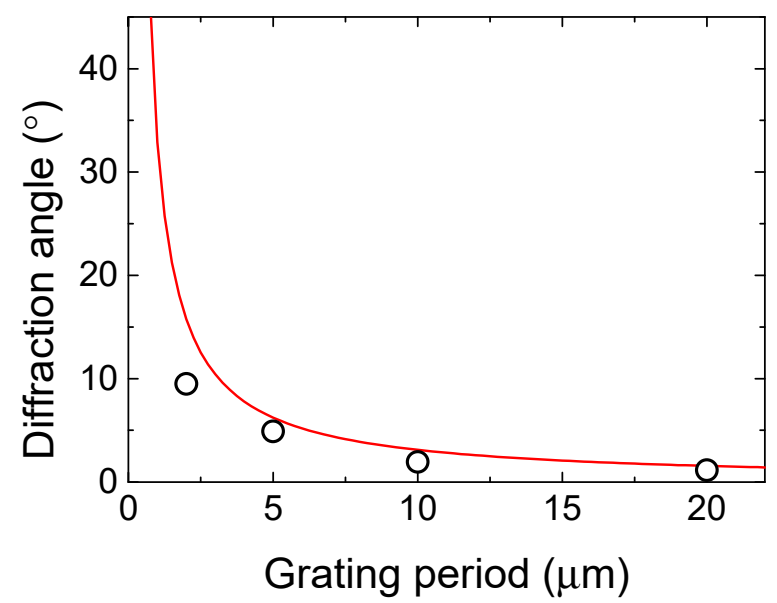

Figure 3. Diffraction angles (dots and line represent measured and calculated results, respectively) at first-order of the ULH cells as a function of grating period $\Lambda$. The thickness of LC cells was set as twice the pitch.

Figure 4 shows the change in first-order diffraction efficiency as a function of the cell gap. The diffraction efficiency is proportional to the square of a sinusoidal function with a period of $(\pi \Delta n d) /(\lambda \cos \beta)$, where $\lambda$ and $\beta$ are the wavelength and the incident angle of the probe beam, respectively; $d$ is the thickness of the liquid crystal layer; $\Delta n$ is the refractive index difference in the grating [31]. As shown in Figure 1, the measured results (dots) show the same periodicity with the proportional expression.

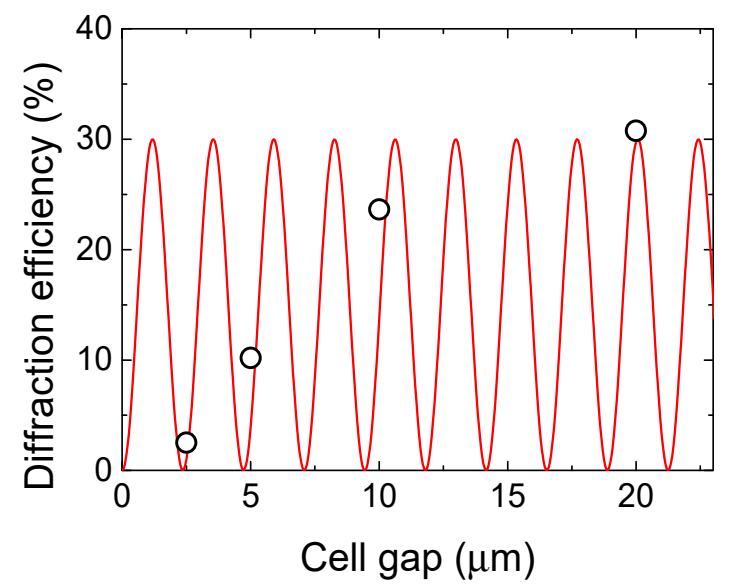

Figure 4. First-order diffraction efficiency (dots and line represent measured and fitted results with the proportional expression, respectively) of the ULH cells as a function of the cell gap. The thickness of LC cells was set as twice the pitch.

With a cell gap of $2.5 \mu \mathrm{m}$, the fabricated ULH cell showed a large diffraction angle, but the diffraction efficiency was relatively low (2.5\%). With the fixed pitch length, which is associated with the grating period, we can maximize the diffraction efficiency by optimizing the cell gap. Figure 5 shows the diffraction efficiency of the fabricated ULH cell as a function of the cell gap for a fixed pitch length of $1.25 \mu \mathrm{m}$. We varied the cell gap within the range of $1.44<d / p<4$, which is required to maintain the fingerprint states. The diffraction efficiency was highest at a cell gap of $3.5 \mu \mathrm{m}$. As shown in Figure 5, the diffraction efficiency can be increased simply by optimizing the cell gap. 


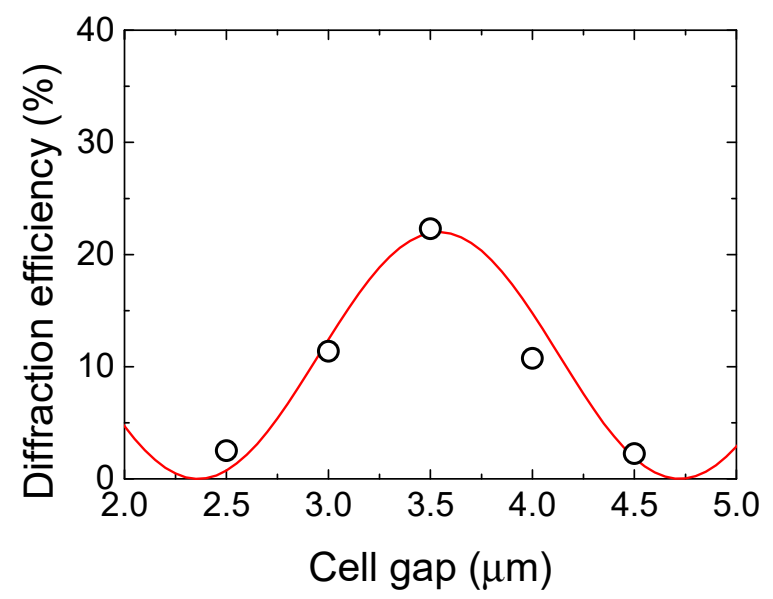

Figure 5. Diffraction efficiency (dots and line represent measured and fitted results with the proportional expression, respectively) at first-order of the ULH cells by changing the cell gap with a fixed pitch length of $1.25 \mu \mathrm{m}$.

The diffraction efficiency can also be affected by the wavelength of the incident light. Figure 6 shows the wavelength dependence of the diffraction efficiency with the cell gap as a parameter. We found that, once the wavelength of the incident light is chosen, we can maximize the diffraction efficiency by optimizing the cell gap of a ULH cell.
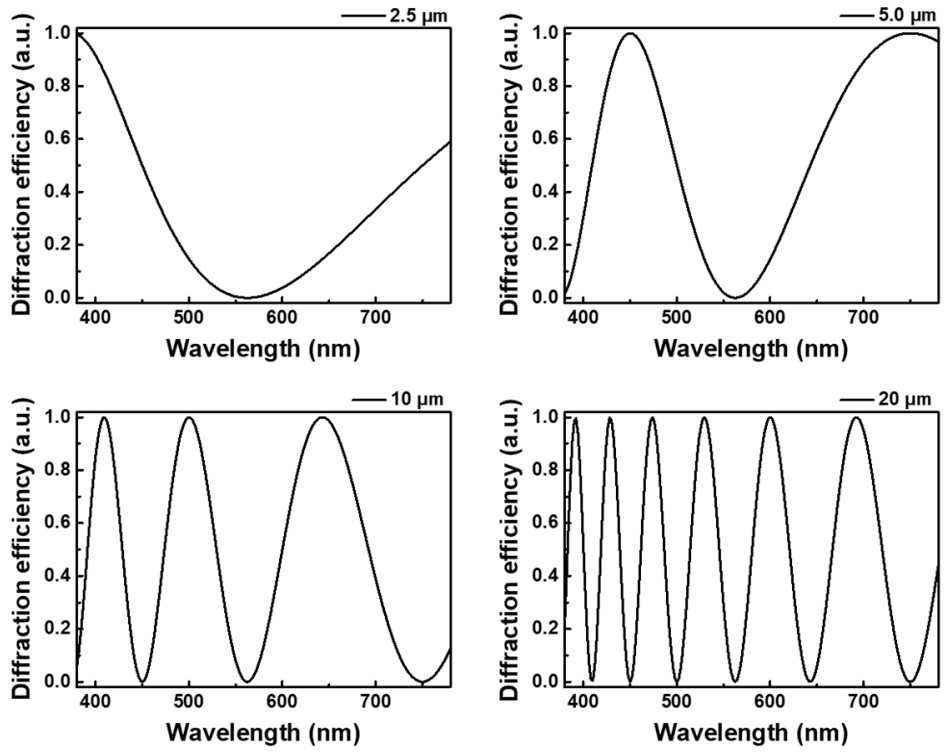

Figure 6. The diffraction efficiency of the ULH cells as a function of the wavelength of incident light with the cell gap of $2.5,5,10$, and $20 \mu \mathrm{m}$. The pitch of ChLCs were set as half of the cell gap.

The fabricated ULH cell is switchable by merely applying a voltage wave. Figure $7 \mathrm{a}$ shows the schematic operation of the fabricated ULH cell. Initially, the incident light is diffracted by the ULH texture. When a vertical electric field is applied to the cell, the LC molecules are reoriented along the vertical direction. Therefore, the light passes through the cell with no diffraction. Figure $7 \mathrm{~b}$ shows the measured diffraction efficiency for each order $\eta_{m}=I_{m} / I_{0}$ as the applied voltage is increased. Initially, the diffraction efficiency of the zeroth-, first-, and second-order was $66.1 \%, 19.5 \%$, and $8.4 \%$, respectively. As expected, the increase in the applied voltage led to increased zeroth-order efficiency and a decrease in other orders. When the applied voltage was over $3 \mathrm{~V}$, the diffraction efficiency of the zeroth-order became $93.7 \%$. The fabricated ULH cell can be switched at a low operating voltage of $3 \mathrm{~V}$. 
a

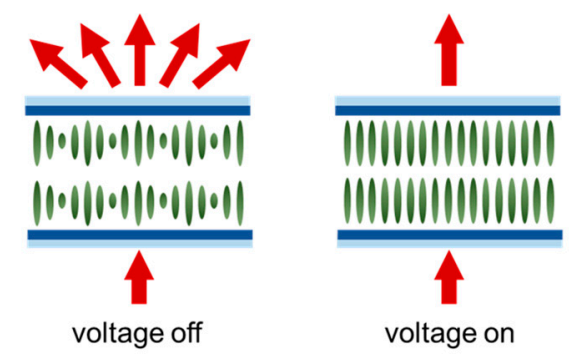

b

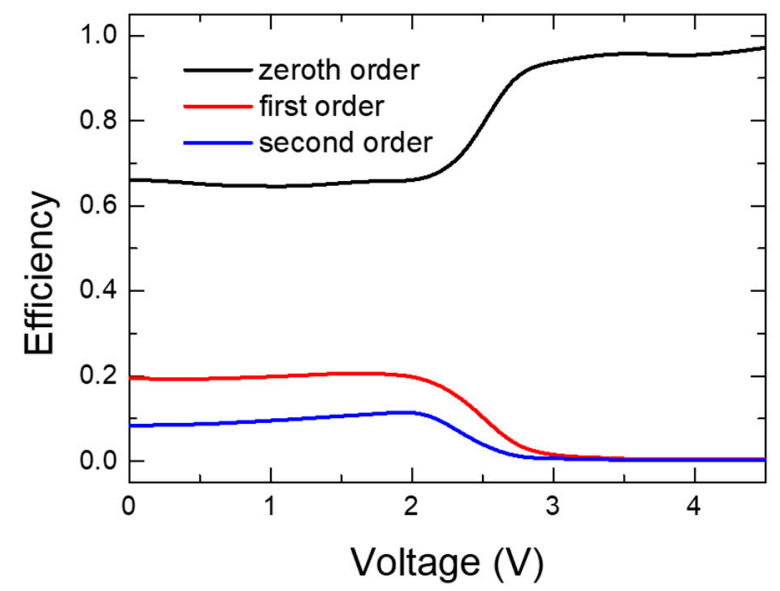

Figure 7. (a) Schematic representation of ULH polarization grating. (b) The measured voltagedependent diffraction efficiency for each diffraction order of the fabricated ULH cell with a cell gap and the pitch length of 3.5 and $1.25 \mu \mathrm{m}$, respectively.

\section{Conclusions}

In summary, we have demonstrated a simple fabrication method of ULH cells for phase grating device applications. First, we found the condition for which the helical axis is aligned parallel to the substrates. Then, we fabricated the ULH cell by aligning LCs in one direction through the mechanical rubbing process. We measured the diffraction properties, such as diffraction angle and diffraction efficiency, and compared them with the calculated results. We confirmed that the diffraction efficiency could be maximized by optimizing the cell gap. It is switchable by merely controlling the applied voltage with a low operating voltage of $3 \mathrm{~V}$. We can expect potential applications for diffraction optics, optical interconnect, and beam steering devices.

Author Contributions: S.-W.O. and T.-H.Y. planned the study. H.-J.S. wrote the manuscript; H.-J.S. and S.-W.O. conceived and designed the uniform lying helix cholesteric liquid crystal cell. H.-J.S. and S.-M.J. performed the experiments; H.-J.S., Y.C. and S.-W.O. analyzed the experimental and calculated data; T.-H.Y. supervised the analysis and co-wrote the manuscript. All authors discussed the results and commented on the manuscript at all stages. All authors have read and agreed to the published version of the manuscript.

Funding: This work was supported by the National Research Foundation of Korea (NRF) grant funded by the Korea government (MSIP) (No. 2020R1A2C1006464).

Institutional Review Board Statement: Not applicable.

Informed Consent Statement: Not applicable.

Data Availability Statement: Not applicable.

Conflicts of Interest: The authors declare no conflict of interest. 


\section{References}

1. Shang, X.; Meeus, L.; Cuypers, D.; Smet, H.D. Fast switching cholesteric liquid crystal optical beam deflector with polarization independence. Sci. Rep. 2017, 7, 1-8. [CrossRef]

2. Kim, K.-H.; Jin, H.-J.; Park, K.-H.; Lee, J.-H.; Kim, J.C.; Yoon, T.-H. Long-pitch cholesteric liquid crystal cell for switchable achromatic reflection. Opt. Express 2010, 18, 16745-16750. [CrossRef]

3. Kumar, P.; Kang, S.-W.; Lee, S.-H. Advanced bistable cholesteric light shutter with dual frequency nematic liquid crystal. Opt. Mater. Express 2012, 2, 1121-1134. [CrossRef]

4. Yu, B.-H.; Huh, J.-W.; Kim, K.-H.; Yoon, T.-H. Light shutter using dichroic-dye-doped long-pitch cholesteric liquid crystals. Opt. Express 2013, 21, 29332-29337. [CrossRef]

5. Huh, J.-W.; Yu, B.-H.; Heo, J.; Yoon, T.-H. Double-layered light shutter using long-pitch cholesteric liquid crystal cells. Appl. Opt. 2015, 54, 3792-3795. [CrossRef]

6. Oh, S.-W.; Baek, J.-M.; Heo, J.; Yoon, T.-H. Dye-doped cholesteric liquid crystal light shutter with a polymer-dispersed liquid crystal film. Dye. Pigment. 2016, 134, 36-40. [CrossRef]

7. Oh, S.-W.; Kim, S.-H.; Yoon, T.-H. Thermal control of transmission property by phase transition in cholesteric liquid crystals. J. Mater. Chem. C 2018, 6, 6520-6525. [CrossRef]

8. Cao, W.; Munos, A.; Palffy-Muhoray, P.; Taheri, B. Lasing in a three-dimensional photonic crystal of the liquid crystal blue phase II. Nat. Mater. 2002, 1, 111-113. [CrossRef]

9. Kopp, V.I.; Zhang, Z.-Q.; Genacka, A.Z. Lasing in chiral photonic structures. Prog. Quantum. Electron. 2003, 27, 369-416. [CrossRef]

10. Coles, H.; Morris, S. Liquid-crystal lasers. Nat. Photonics 2010, 4, 676-685. [CrossRef]

11. Xiang, J.; Varanytsia, A.; Minkowski, F.; Paterson, D.A.; Storey, J.M.D.; Imrie, C.T.; Lavrentovich, O.D.; Palffy-Muhoray, P. Electrically tunable laser based on oblique heliconical cholesteric liquid crystal. Proc. Natl. Acad. Sci. USA 2016, 113, 12925-12928. [CrossRef]

12. Ryabchun, A.; Bobrovsky, A. Cholesteric liquid crystal materials for tunable diffractive optics. Adv Opt. Mater. $2018,6,1800335$. [CrossRef]

13. Ortega, J.; Folcia, C.L.; Etxebarria, J. Upgrading the performance of cholesteric liquid crystal lasers: Improvement margins and limitations. Materials 2018, 11, 5. [CrossRef]

14. Subacius, D.; Shiyanovskii, S.V.; Bos, P.; Lavrentovich, O.D. Cholesteric gratings with field-controlled period. Appl. Phys. Lett. 1997, 71, 3323. [CrossRef]

15. Subacius, D.; Bos, P.J.; Lavrentovich, O.D. Switchable diffractive cholesteric gratings. Appl. Phys. Lett. 1997, 71, 1350. [CrossRef]

16. Lee, S.N.; Chien, L.C.; Sprunt, S. Polymer-stabilized diffraction gratings from cholesteric liquid crystals. Appl. Phys. Lett. 1998, 72, 885. [CrossRef]

17. Ryabchun, A.; Bobrovsky, A.; Stumpe, J.; Shibaev, V. Rotatable diffraction gratings based on cholesteric liquid crystals with phototunable helix pitch. Adv. Opt. Mater. 2015, 3, 1273-1279. [CrossRef]

18. Demus, D.; Goodby, J.W.; Gray, G.W.; Spiess, H.W.; Vill, V. Handbook of Liquid Crystals; Wiley-VCH Verlag GmbH \& Co. KGaA: Weinheim, Germany, 2011.

19. Inoue, Y.; Moritake, H. Formation of a defect-free uniform lying helix in a thick cholesteric liquid crystal cell. Appl. Phys. Express 2015, 8, 071701. [CrossRef]

20. Rudquist, P.; Komitov, L.; Lagerwall, S.T. Volume-stabilized ULH structure for the flexoelectro-optic effect and the phase-shift effect in cholesterics. Liq. Cryst. 1998, 24, 329-334. [CrossRef]

21. Komitov, L. Alignment of cholesteric liquid crystals using periodic anchoring. J. Appl. Phys. 1999, 86, 3508. [CrossRef]

22. Carbone, G.; Salter, P.; Elston, S.J.; Raynes, P.; Sio, L.D.; Ferjani, S.; Strangi, G.; Umeton, C.; Bartolino, R. Short pitch cholesteric electro-optical device based on periodic polymer structures. Appl. Phys. Lett. 2009, 95, 011102. [CrossRef]

23. Kim, S.H.; Shi, L.; Chien, L.-C. Fast flexoelectric switching in a cholesteric liquid crystal cell with surface-localized polymer network. J. Phys. D Appl. Phys. 2009, 42, 195102. [CrossRef]

24. Cladis, P.E.; Kléman, M. The cholesteric domain texture. Mol. Cryst. Liq. Cryst. 1972, 16, 1. [CrossRef]

25. Oswald, P.; Baudry, J.; Pirkl, S. Static and dynamic properties of cholesteric fingers in electric field. Phys. Rep. 2000, $337,67$. [CrossRef]

26. Gvozdovskyy, I.; Yaroshchuk, O.; Serbina, M.; Yamaguchi, R. Photoinduced helical inversion in cholesteric liquid crystal cells with homeotropic anchoring. Opt. Express 2012, 20, 3499. [CrossRef]

27. Oh, S.-W.; Baek, J.-M.; Kim, S.-H.; Yoon, T.-H. Optical and electrical switching of cholesteric liquid crystals containing azo dye. RSC Adv. 2017, 7, 19497. [CrossRef]

28. Oh, S.-W.; Kim, S.-H.; Baek, J.-M.; Yoon, T.-H. Optical and thermal switching of liquid crystals for self-shading windows. Adv. Sustain. Syst. 2018, 2, 1700164. [CrossRef]

29. Hegde, G.; Komitov, L. Periodic anchoring condition for alignment of a short pitch cholesteric liquid crystal in uniform lying helix texture. Appl. Phys. Lett. 2010, 96, 113503. [CrossRef] 
30. Kobashi, J.; Mohri, Y.; Yoshida, H.; Ozaki, M. Circularly-polarized, large-angle reflective deflectors based on periodically patterned cholesteric liquid crystals. Opt. Data Process. Storage 2017, 3, 61-66. [CrossRef]

31. Huang, S.-Y.; Huang, B.-Y.; Kang, C.-C.; Kuo, C.-T. Diffraction and polarization properties of electrically-tunable nematic liquid crystal grating. Polymers 2020, 12, 1929. [CrossRef] 